\title{
The mathematical creativity of Ramanujan FRS (1887-1920)
}

\author{
Peter Merrotsy \\ The University of Western Australia
}

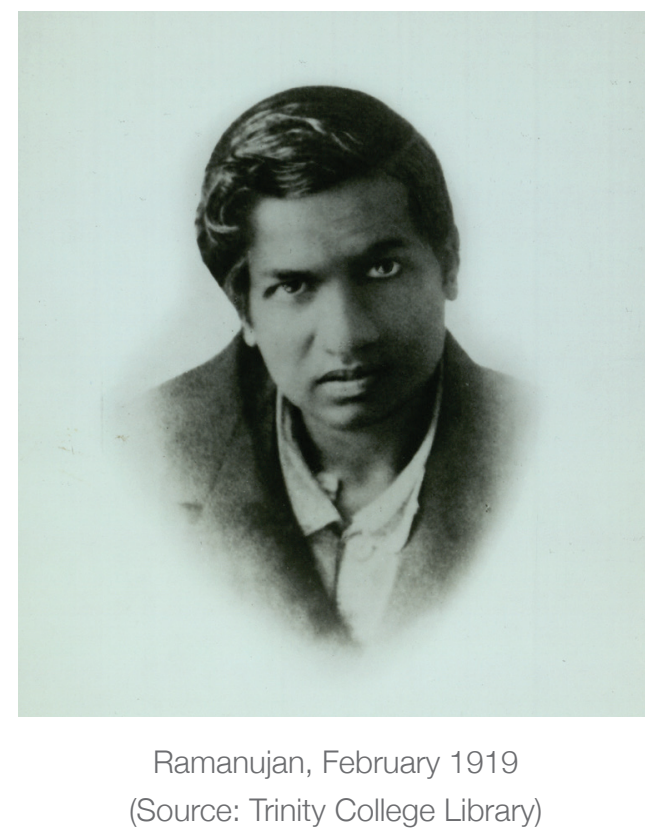

\begin{abstract}
The occasion of the centenary of his death provides a poignant opportunity to reflect on the mathematical creativity of Ramanujan, on the cultural and social milieu in which he grew up, and on the educational experiences that informed his development. Attention is drawn to the deep nature of his discoveries in number theory, set alongside a sketch of the humble person who created so many wild and fantastic theorems.
\end{abstract}




\section{Mathematical creativity}

The classical and standard definition of creativity was proposed by Stein (1953, p. 311; cf. Runco \& Jaeger, 2012):

The creative work is a novel work that is accepted as tenable or useful or satisfying by a group in some point in time. ... By 'novel' I mean that the creative product did not exist previously in precisely the same form.

At the same time, Stein (1953) drew attention to the difference between objective and subjective forms of creativity. He observed that "often, in studying creativity, we tend to restrict ourselves to a study of the genius because the distance between what he $[s i c]$ has done and what has existed is quite marked" (p. 311). This tendency for researchers to focus on geniustype creativity, Stein argued, "causes us to overlook a necessary distinction between the creative product and the creative experience" (p. 311f.).

In mathematics, however, it is not possible to separate the creative product from the creative experience. In mathematics, the novel work may be presented, for example, as a theorem, which is clearly a product. However, the process through which this product is created is in itself also a product. The method - the process of intuition, conjecture, plausibility, and proof of the theorem - is just as important as the theorem by itself, if not more important. To understand and appreciate mathematical creativity, we need to examine both the process and the product of invention and discovery together. This is true, too, when we focus on the creativity of the mathematical genius: it is not possible to separate their creative mathematical results from their creative mathematical experience.

A related issue is the extent to which mathematical creativity can be measured, especially the creativity of the mathematical genius. For example, perhaps it is not appropriate, and indeed not possible, to measure and compare the far-reaching work of Apollonius on conic sections and eccentric orbits, which lay dormant, unrecognised, unacknowledged, essentially unknown until, more than 1.800 years later, it was suddenly understood and appreciated and used to such remarkably good effect by Kepler; the prodigious cuvre of Euler, which increased in rate of output after he became blind; the extraordinary fecundity of the mind of Erdős, well known for having an Erdős number of zero; the breadth, sharpness, depth and foresight of Riemann's handful of publications, foundational and influential across five areas of mathematics; and the world-shattering impact of Galois' one paper, unpublished in his short lifetime.

That is not to say that we should not attempt to measure mathematical creativity, nor that good sense cannot be gained from doing so. One measure I like is to compare the development of a concept over time. As an indicator of mathematical creativity, the growing complexity of several expressions for $\pi$ are shown in Table 1. The first three results are approximations that an engineer might use. Results 4 to 10 and 12 are all related, and comprise a neat reflection of developments in mathematics over two millennia. The leap by Euler (result 11) represents a significant shift in the area of mathematical analysis. Result 13 relies on the proof of the transcendence of $e$, which drew on 19th century developments in algebra, in particular Galois theory. Result 14, as is apparent by simple observation, is astounding, and remarkably different from all of the previous results. The distance (sensu Stein, above) between this result and what had previously existed is more than quite marked - it is enormous, both quantitatively and qualitatively.

Another measure of mathematical creativity is to ask the experts, to ask mathematicians for their judgement. For example, in Hardy's (1940) list of natural mathematical talent, Hardy rated himself 25, Littlewood 30, and Hilbert 80; the author of the 14th result was rated by Hardy at 100. Erdős said that the author of result 14 was the most naturally talented 
mathematician ever in the world (Berndt \& Rankin, 2001). The author of result 14 was Ramanujan. And for Ramanujan, it is certainly not possible to separate the creative product from the creative experience.

\section{Table 1:}

Approximations to $\pi$ (Sources: Katz, 2018; Ramanujan, 1914; Stillwell, 2010).

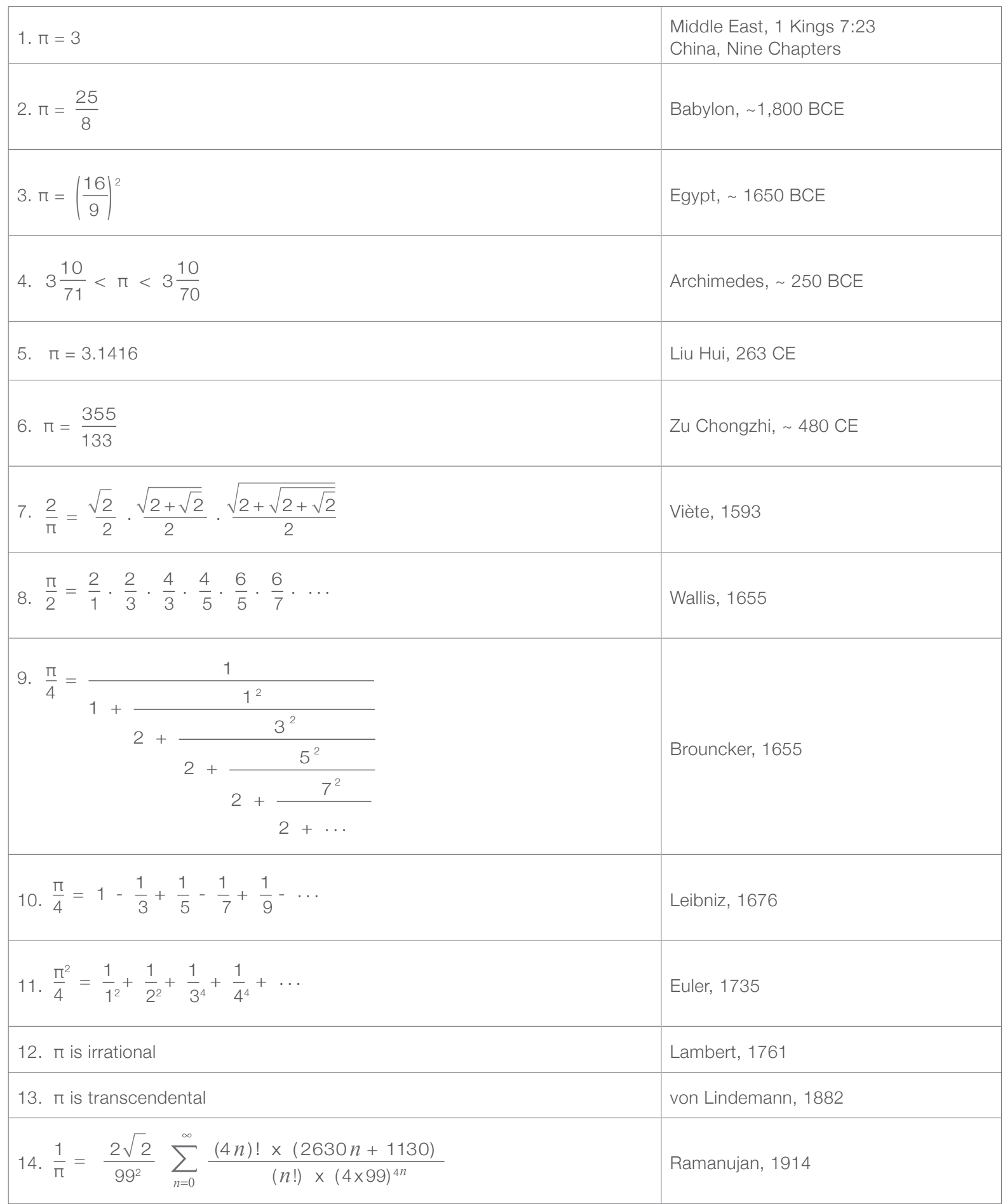




\section{Ramanujan's cultural and social background}

Ramanujan was born in 1887 , on the ninth day of Margasirsha in the Samvath Sarvajit, that is, 22 December, which, for very good reason, has become India's National Mathematics Day. Following tradition, Ramanujan was born in the house of his maternal grandfather on Alagiri Singh Street in Erode. Erode is situated on the banks of the River Kaveri (also spelt Cauvery) in Tamil Nadu in southern India, about 400 $\mathrm{km}$ south west of Chennai. It was, and still is, a large rural centre: in 1887 the population was about 15,000 (the population in 2010 was approximately 500,000); then, its economy was based mainly on agriculture, and it was important for the production of textiles and turmeric, and that is still the case today. Alagiri Singh Street lies in the heart of the textile district of Erode, and is surrounded by several temples, several mandapam (temple porch or pavilion for public rituals), and theppakulam (a temple pool used for special religious festivals).

Ramanujan was born into a strictly orthodox Hindu Brahmin family of extremely modest circumstances. The family's kula dheivam (deity) was Sri Namagiri Thayar of Namakkal. Namakkal, a rural town $60 \mathrm{~km}$ east of Erode, is dominated by a granite outcrop. At the foot of this massive dome of rock are several temples and sacred pools. In the Anjaneyar temple the 5th century image of Anjaneyar (one of the names of the Hindu god Hanuman) is carved out of a single block of stone and stands 5.5 metres tall. Anjaneyar looks directly towards the 7th century image of Narasimha, the lion faced avasara (incarnation) of the god Vishnu, which is carved directly into the base of the granite outcrop. Narasimha is a powerful protector against evil, and "the sign of his grace consists in drops of blood seen during dreams" (Ranganathan, 1967, p. 87). Close to the cave temple of Narasimha and also facing his image stands a shrine for his consort Namagiri, an avasara of the goddess Lakshmi.
Ramanujan's father, Srinivasa, was a gumasta (petty clerk) in a cloth merchant's shop, earning the marginal salary of about 20 Rupees per month; his mother Komalathammal sang in a temple, which supplemented the family income. After their marriage, Komalathammal did not conceive for many years. It is said that her mother prayed to Namagiri for a grandchild, and that Namagiri said to her, "I shall be in the tongue of the eldest born" (Document, Institute of Mathematical Sciences, Chennai).

Srinivasa named their first child Ramanujan, which means Rama anujan, the younger brother of Rama, whose name was Lakshmanan. Sometimes Ramanujan is written in the Sanskrit form Ramanujaha, or written Ramanujam because in Tamil the final consonant sounds half way between $\mathrm{n}$ and $\mathrm{m}$. Often the full titled name Srinivasa Ramanujan Iyengar is written: Srinivasa is patronymic, acknowledgement that Srinivasa was his father; Iyengar (alternatively, Aiyengar, Aiyangar, or Ayyangar) is the caste title of the orthodox Brahmin Sri Vaishnavites. His friends called him Ramanja. Komalathammal called him Chinnaswami, which roughly translates as Little Lord. But Ramanujan's full name is just his given name: he was, simply, ராமானాஜன - Ramanujan.

Ramanujan was the first of six children: two brothers, Lakshmi Narasimhan (1898-1946), and Tirunarayanan (1905-1978) survived to adulthood; three siblings died in early childhood (brothers Sadagopan and Seshan, sister Ambujavalli - some records add two more unnamed sisters). According to Guha (1991), in Tamil Nadu between 1890 and 1900 there were approximately 200-240 deaths of infants less than one year old per 1,000 live births, and life expectancy at birth was 23 years. The link between a high rate of infant mortality and poverty is well documented (Oxfam, 2019). In Tamil Nadu, the effects of poverty are accentuated by malnutrition and anaemia, and are exacerbated by the presence of a high number of infectious diseases, such as malaria, hepatitis A, yellow fever, diphtheria, small pox, 
dengue, Japanese encephalitis, rabies, typhoid, enteric fever, and diarrhoea.

Following tradition, nine months after the birth Komalathammal returned with the infant Ramanujan to Srinivasa and the family home in Kumbakonam. Kumbakonam (also written Kumbhakonam) is a low-lying town in the River Kaveri delta, situated 220 $\mathrm{km}$ east of Erode and $280 \mathrm{~km}$ south of Chennai, or Madras as it was previously known. It is an ancient centre of Tamil culture, a town of pilgrimage, famous for its extraordinary number of temples, shrines, mandapam, and theppakulam, including the Mahamaham tank which is the site of an important Hindu festival held once every 12 years. One of the great temples in Kumbakonam is the Vaishnavite Sarangapani Temple - sarangapani means one who has the bow in his hand. The temple's ornate and colourful rajagopuram (main entrance) stands over 50 metres high. In front of the entrance stands an intricately carved wooden temple chariot. Through the entrance is found the huge temple complex measuring 160 metres by 60 metres, with hundreds of stone columns leading to the main shrine, created in the form of a chariot drawn by elephants and horses and carved from granite. The Potramarai holy tank lies behind the temple. (Information booklet, Sri Sarangapani Swamy Temple.)

Heading east away from the Sarangapani Temple runs Sarangapani koil sannidhi Street, that is, the road leading to the sannidhi (main entrance) of the koil (temple) for the god Sarangapani. On the left-hand side about one minute's walk from the rajagopuram is number 17 , a low and narrow house set about one metre back from the street. The title deeds to the house, on display inside, show that the house was bought by Srinivasa's family in 1861 . At the front of the house there is a small pial (a covered porch), set off by two wooden columns. Through the low front doorway, along the length of the house, there is a narrow hall, giving access to four small rooms. Behind the pial, behind a gridded open window with a bench, there is a bedroom with space for one bed. Then there is a semi-open room, with an open skylight, and here people could sit and talk, eat, worship at the family shrine, and sleep on the floor. Next there is a storage room. The fourth room, at the rear end of the house, is a kitchen. The cooking "stove" is a fireplace fuelled by burning dung or sticks of wood, about $40 \mathrm{~cm}$ by $20 \mathrm{~cm}$ in size, with three sides made from baked clay about $20 \mathrm{~cm}$ high, on which could be placed one or two pots; there is no chimney. Behind the house and down some steps there is a small enclosed courtyard, with a well, and with a stone for washing clothes.

\section{Ramanujan's education}

As a child and as an adult Ramanujan was short of stature, as are most people in Tamil Nadu. Even though he grew up in a very poor family, and sometimes there was no food, for most of his life Ramanujan was plump or chubby, which is certainly not common in Tamil Nadu. When he was an adolescent he became quite overweight, and joked at times that "if anybody comes to quarrel, I'll fall on them and crush them" (Berndt \& Rankin, 2001, p. 31).

During his childhood, and as an adult before going to Cambridge, Ramanujan had a bun or top knot, and shaved his forehead. Each day, a tilaka was marked on his forehead, which for Ramanujan was a thenkalai urdhva pundra, the white and red tridentlike marking of the Thenkalai sect of the Iyengar caste of the Vaishnava Hindu Brahmins: the white U-shape chandan from clay and sandalwood paste represents the lotus feet of Vishnu; the red tear-drop shape from vermilion represents Lakshmi, the consort of Vishnu. Ramanujan wore a janeu (sacred thread) across his chest, and a white dhoti (and definitely not the blue and brown lungi); in Madras he also wore an open jacket, which would have indicated his rural background.

It is said (Berndt \& Rankin, 2001) that Ramanujan did not speak ("remained dumb", p. 31) until 1892, when he was 4 years old. It is also said that he had a difficult temperament, prone at times to becoming agitated or 
having childhood tantrums, especially when he was hungry, which earned him the nickname keerippillai (mongoose). Here a caveat should be noted that, while some would argue that Ramanujan "had" Asperger's disorder or Asperger's syndrome (Fitzgerald, 2002, passim.), we must affirm that any such post hoc diagnosis is not appropriate, and say, quietly but firmly, "No!" to such claims. In any case, according to the judgement of others (Berndt \& Rankin, 1995; Berndt \& Rankin, 2001; Hardy, 1940; Kanigel, 1991; Ranganathan, 1967), Ramanujan was by all accounts quiet, shy, reserved, very humble, very polite towards others, naïve, absent minded, free from affectation, extremely modest, and with a child-like simplicity and no trace of self-consciousness related to his abilities. He was always a serious student, and even when young could concentrate on a single task for many hours. At the same time, he was full of humour, friendly, and sociable; and a good conversationalist who could talk for many hours and long into the night about Tamil culture and Hindu religion. People liked him. And, above all, he had one conspicuous feature: bright, glistening eyes.

In October 1892, Ramanujan attended a kind of kindergarten, but he did not like sitting with his arms folded, and he objected to other kinds of discipline, to which he often responded by simply leaving the class and going home. In December 1892, Ramanujan began primary school, and contracted smallpox, which left permanent scars on his face. At this time, his father Srinivasa was dismissed from his job, which meant that he had to travel to find work and was often away from home for long periods of time. Occasionally Ramanujan had to go to school on an empty stomach, but over time the tantrums ceased, which coincided with the time when he began to dream solutions to mathematical problems and puzzles that he met at school (Document, Ramanujan Museum, Royapuram, Chennai). Towards the end of 1897 he passed his primary school examinations with the highest scores in the district, and proceeded to high school.
By the time Ramanujan started to attend Town High School in Kumbakonam in 1898, he knew the prime numbers up to 1 crore (10 million), and was asking interesting (and, for a teacher, perhaps challenging) questions such as what is the result when zero is divided by zero. Then in 1901, when he was 13 years old and a student in Form IV, Class 9, he was lent a copy of Loney (1893) Plane trigonometry (this is still used as a text in southern India, and I was able to buy a copy of both volumes at the Higginbothams bookshop in Chennai for 215 Rupees $\sim \$ 4)$. Loney (1893) quickly covers and goes well past trigonometry topics typically dealt with in advanced courses in senior secondary mathematics, before venturing into power series, hyperbolic functions, and logarithms of a complex variable. Ramanujan mastered the contents by himself, and from this he started to develop his own results; later he learnt that some of what he discovered were in fact re-discoveries of known results, which embarrassed him and he hid them.

In 1903, something strange and remarkable happened. A friend provided Ramanujan with a copy of Carr's Synopsis. It is not clear from the biographical literature whether this was the 1880 or the 1886 edition, but from what later transpired I suspect that it is the twovolume edition from 1886. In any case, as a synopsis of elementary results in pure mathematics it was (and still is) anything but elementary. It was written as an aid for students preparing for their final honours or masters level degree examinations in mathematics, especially for the high-level Cambridge Mathematical Tripos. Volume 1 contains sections on mathematical tables; algebra; the theory of equations; plane trigonometry; spherical trigonometry; "elementary" geometry; and geometrical conics. Volume 2 contains sections on differential calculus; calculus of variations; calculus of finite differences; and plane coordinate geometry, including analytical conics and plane curves. Together the two volumes contain 935 pages (plus fold-out pages with 193 diagrams) presenting 4,417 entries (numbered up to 6,165) comprising propositions, formulæ, and methods of analysis, all without proof. For an indication of the terseness and depth of the 
contents, it is possible to access both editions on the Internet, and a glance at any page opened at random will indicate what confronted Ramanujan.

Ramanujan systematically worked through the lot, establishing each result, and began investigations that would take many of the results to a far, far deeper level. At 15 years of age, in Form VI, Class 11 at his small, rural high school, Ramanujan became obsessed, addicted to exploring mathematics. The inspiration for his mathematical discoveries, he said, came from the goddess Namagiri, who also revealed in dreams solutions to problems that Ramanujan was working on. Ramanujan also reported dreams in which appeared drops of blood followed by scrolls containing mathematical formulae. On one such occasion:

There was a red screen formed by flowing blood as it were. I was observing it. Suddenly a hand began to write on the screen. I became all attention. That hand wrote a number of results in elliptic integrals. They stuck to my mind. As soon as I woke up, I committed them to writing. (Ranganathan, 1967, p. 87.)

Blood, however, is a sign of the god Narasimha (a point missed by most biographies of Ramanujan, which focus on the role of Namagiri): both Namagiri and Narasimha were sources of Ramanujan's mathematical inspiration and revelations.

After matriculating in 1904 with many academic prizes (the school principal stated that Ramanujan "deserved higher than the maximum possible marks," Kanigel, 1991, p. 27) Ramanujan attended the Government Arts College in Kumbakonam on scholarship, and studied for the First Examination in Arts. But his was not a well-rounded education: in 1905, Ramanujan failed English; and he lost his scholarship funds. Biographies (for example, Kanigel, 1991) say that at this time Ramanujan ran away from home due to shame, but the truth may well be that he was looking, unsuccessfully, for a sponsor to support his mathematical studies. In any case, he had not gained the qualification necessary for entry into the University of Madras.

In the following year, Ramanujan again studied for the First Examination in Arts, but this time at Pachaiappa's College, George Town, Madras, and lived near the George Town Fruit Bazaar with his grandmother. Here there was a sign of promise: the principal of the college, having seen one of the notebooks in which Ramanujan recorded his mathematical results (Ramanujan Aiyangar, 2012), offered a partial scholarship. However, in the second half of the year, Ramanujan became seriously ill, and returned to Kumbakonam for three months. The seriousness of this illness should not be glossed over - in case he was to die, Ramanujan entrusted his Notebooks to a friend (Ranganathan, 1967; Young, 1994). At the end of the 1906 academic year, Ramanujan failed the First Examination in Arts for the second time.

Eking out a meagre subsistence by tutoring university students in mathematics, Ramanujan spent 1907 studying for the First Examination in Arts privately. $\mathrm{He}$ spent most of the time working on his mathematics. At his third attempt, Ramanujan failed English, Sanskrit, physiology and history (a copy of the original academic record is found in Berndt \& Rankin, 2001), marking the end of his "formal" studies. Too poor to continue, Ramanujan returned to Kumbakonam.

\section{Leisure to dream on}

For two years, seated on the pial of the family house, or on the bench behind the front window, or in the cool of the Sarangapani Temple, Ramanujan laboured on his mathematics, scratching through problems and developing ideas with a stylus on a large writing tablet made from real slate (Bruce Berndt, personal communication, 10 June 2019), erasing with his elbow as he proceeded, and writing in his Notebook just the final results as they were found. Komalathammal, however, had other ideas for her son. Following tradition, with a friend Ranganayaki from the village 
Rajendram, lying upstream on the River Kaveri about $100 \mathrm{~km}$ west of Kumbakonam, she negotiated a marriage between Ramanujan and Ranganayaki's daughter Janaki (1899-1994). The wedding did not pass without incident (the train was delayed, a bad omen indeed), and appeared to proceed without the blessing of Ramanujan's father, Srinivasa. At 21 years of age, and with no formal qualifications, Ramanujan had responsibility for a nine-year-old wife and was increasingly obliged to seek employment. (Document, Institute of Mathematical Sciences, Chennai.)

The search for employment to support his wife and his aging parents took Ramanujan back to Madras. In reality, he was looking for sponsors for "leisure" to do his mathematics, opportunity, that is, to pursue his studies and for "simple food to be provided for him without exertion on his part and that he should be allowed to dream on" (Ramachandra Rao, 1920, p. 87). But, again in reality, Ramanujan had to accept whatever he could find. What is clear is that for at least two years he lived in utter poverty: he relied on charity from friends for food, and was often hungry; and he relied on charity from friends for lodgings, staying in many places (the modern equivalent would be couch surfing) in George Town, and in Triplicane near the Arulmigu Sri Parthasarathyswamy and Arulmigu Thulasinga Perumal temple complex and pool, and not far from the University of Madras (Ranganathan, 1967). For a total of six weeks in 1911, he found employment as a clerk on 20 Rupees per month.

Ramanujan then sought out members of the recently formed Indian Mathematics Society. Eventually, and by chance, he was granted an audience with Ramachandra Rao, a mathematician and secretary of the society, and who was a Brahmin, and wealthy and well connected. In his obituary for Ramanujan, Ramachandra Rao (1920, p. 87) wrote:

In the plenitude of my mathematical wisdom, I condescended to permit Ramanujan to walk into my presence. A short uncouth figure, stout, unshaved, not over-clean, with one conspicuous feature - shining eyes - walked in, with a frayed Notebook under his arm. He was miserably poor.

Following this meeting, there did follow a time of "leisure" afforded by financial support from Ramachandra Rao, during which Ramanujan began to publish in the Journal of the Indian Mathematics Society. His contributions included problems and solutions to problems (Berndt, Choi \& Kang, 1999), and five papers, notably his first paper titled "Some properties of Bernoulli's numbers" and written in his inimitable terse style, and brief papers on a set of simultaneous equations, irregular numbers, and squaring the circle using $\pi \approx \frac{355}{113}$ (Hardy, Seshu Aiyar \& Wilson, 1927).

However, the charity must have embarrassed Ramanujan, and after about one year he declined it and through the help of his mathematical friends was appointed to the position of clerk, Number 16, Class III, 4th grade, at Madras Port Trust, on a salary of 25 Rupees per month.

At this time, encouraged by members of the Indian Mathematics Society and their connections, Ramanujan wrote to European mathematicians in the hope of finding someone who could understand his work, give him encouragement, and help him to publish. Letters to two English mathematicians (Professor H.F. Baker, and Professor E.W Hobson) were returned, opened but with no response. Perhaps they were affronted by results such as

$$
\sum n=\frac{-1}{12}, \sum n^{2}=0 \text { and } \sum n^{3}=\frac{-1}{240}
$$

but what they had missed is that these seemingly nonsensible results are in fact hiding something much deeper related to the Riemann zeta function. And then, probably prompted by a recent journal article on the number of primes less than a given number, about which he claimed to have a far deeper result, Ramanujan wrote to a third English mathematician. 


\section{Ramanujan and Hardy}

On 2 February 1913, England's leading mathematician Professor G.H. Hardy, Trinity College, Cambridge University, opened an untidy envelope with many Indian postage stamps to find on crumpled pages an unsolicited letter, dated 16 January 1913, from an unknown Hindu clerk, which began:

Dear Sir, I beg to introduce myself to you as a clerk in the Accounts Department of the Port Trust Office at Madras on a salary of only $£ 20$ per annum. I am now about 23 [sic] years of age. I have had no University education but I have undergone the ordinary school course. After leaving school I have been employing the spare time at my disposal to work at Mathematics. (Hardy, 1921, p. xlii.)

There followed eleven pages of mathematical formulæ, wild and fantastic theorems on prime numbers, infinite series, integrals, and continued fractions (for those who seek a copy of these pages, note that pages 8 and 10 are lost). Hardy's first reaction was one of irritation at the large number of theorems stated without proof: perhaps the author was a crank, or the letter an elaborate fraud; or perhaps this was a well-crafted practical joke by a colleague. However, Hardy was intrigued, and at the end of his typical and routine Cambridge day his second reaction was to meet with his colleague J.E. Littlewood and to work as best they could through the theorems. Some were vaguely familiar; some looked accessible, but were surprisingly difficult. And yet others were nothing like anything that they had seen before. It was clear that these pages must have been hiding very deep generalisations.

A single look at them is enough to show that they could only be written down by a mathematician of the highest class. They must be true because, if they were not true, no one would have had the imagination to invent them. (Hardy, 1940, p. 9.)
Three hours later, especially when several beautiful results related to continued fractions defeated them completely, they knew for certain: the writer of the letter was a mathematical genius. (Hardy, 1940; see also C.P. Snow, Foreword, in Hardy, 1967.)

It was by no means an easy task to bring Ramanujan to Cambridge University. For a Brahmin, crossing the ocean would mean losing caste, becoming an outcast in his Indian Brahmin community, with serious social consequences such as not being invited to Brahmin weddings and funerals (and, later, Brahmin relatives did not attend Ramanujan's funeral). However, Ramanujan travelled to Namakkal, and spent a full day meditating and praying at the shrine of Namagiri, who revealed to him in a dream that he should go to Cambridge. Apparently, too, Namagiri appeared in a dream to Ramanujan's mother Komalathammal, and "commanded her not to stand in the way of her son fulfilling his life's purpose" (Hardy, Seshu Aiyar \& Wilson, 1927, p. xvi).

Ramanujan arrived in England in April 1914, but of course had to leave his very young wife Janaki behind, entrusted to the care (if that is the correct word!) of his mother Komalathammal. There then followed considerable hardships, exacerbated by the outbreak of World War I. It was difficult, for example, to find vegetables, spices and other ingredients for his strict vegetarian diet. He was able to buy some of these groceries from London, and he received packages from home containing tamarind, narthangaai (a fruit), kuzhuvidam (a kind of bread made from rice or tapioca flour), and coconut oil, which he used to prepare his own meals, cooked on a small stove in his college room. And he was confronted by racism. (Berndt \& Rankin, 1995; Ranganathan, 1967.) During his first winter in Cambridge, Ramanujan began to feel unwell.

For the three years 1914 to 1917, Ramanujan worked with Hardy as his academic mentor, and published 21 journal articles of the highest quality (16 as a sole author, and 5 in collaboration with Hardy). These research papers ranged from partitions (including the 
"circle method", one of the most powerful tools used to approach problems in additive number theory), primes, highly composite numbers, and combinatorics; to definite integrals, elliptic functions, infinite series, Euler's constant, Gauss sums, the Riemann zeta function and quadratic forms; and to modular equations, the tau function, q-series, and theta functions.

Then in 1917 Ramanujan became very ill.

During 1917 and 1918 Ramanujan spent most of the time in nursing homes and in a sanatorium. He was seriously depressed, and there was a possible attempt at suicide due to the depression and persistent pain (Young, 1994). In 1918, he received two prestigious and auspicious awards. First, he was elected a Fellow of the Royal Society, one of the youngest and the second Indian to be so honoured - ironically, two of the signatories to the election were Baker and Hobson, the mathematicians who had returned Ramanujan's correspondence without comment (Berndt \& Rankin, 2001). Second, as well as being elected a Fellow of the Cambridge Philosophical Society, he became the first Indian to be elected a Fellow of Trinity College, Cambridge University.

In March 1919, Ramanujan returned to India. He was looked after by Janaki, and continued to work on his mathematics until four days before his death, when the pain became too great to be able to concentrate. A final letter to Hardy outlined the development of a new and important area of mathematics that Ramanujan called mock theta functions, which was more fully explored in 138 pages of loose-leaf manuscripts that became lost (Berndt \& Rankin, 1995). His discovery of the mock theta functions clearly shows that "his skill and ingenuity did not desert him at the oncoming of his untimely end" (Watson, 2001, p. 347). Ramanujan died on 26 April 1920, in Chetpet, Madras (now Chennai). The diagnosis of his illness in England had been tuberculosis. More recently, it has been suspected that his symptoms were that of hepatic amoebiasis, a curable (or at least treatable) parasitic protozoal infection of the intestine or liver, also known as tropical liver abscess (Young, 1994.). The disease was (and still is) widespread in India, especially in large coastal cities. Perhaps Ramanujan contracted this disease when he became ill in Madras in 1906, with a relapse in 1909, and, noting that "relapses occur when the host-parasite relationship is disturbed" (Young, 1994, p. 113), with a further relapse during that first cold winter in Cambridge in 1914-15.

\section{Ramanujan's intuition, and mathematical rigour}

For much of his life, until 1914 when he was 26 years old, Ramanujan worked in isolation. In India no one was able to follow the flights of his imagination and creativity; in Europe very few were able to approach an understanding of his work; and even today many of his insights and results demand specialist knowledge in very advanced areas of number theory and analysis. It is commonly stated that Ramanujan was "discovered" by Hardy (for example, Hardy, 1967, p. 148). But in fact it was Ramanujan who chose Hardy; Hardy championed Ramanujan. Ramanujan discovered himself. His brilliant intuition and his creativity were painstakingly scratched and rubbed into his individual form of expression through long, arduous hours labouring on his stone slate.

Ramanujan recorded in his Notebooks (Ramanujan Aiyangar, 1988, 2012) between 3,000 and 4,000 theorems (the number depends on how they are counted). About one third of his results were rediscoveries of theorems that had been developed by great European mathematicians over the preceding century or more: for example, he re-discovered the functional equation for the Riemann zeta function, and most of the classical theorems of hypergeometric series, often in barely recognisable form; and he wrote that all of his investigations were based on his exploration of the gamma function (Berndt \& Rankin, 1995, p. 21). He was, as it were, a "poor and solitary Hindu pitting his brains against the accumulated wisdom of Europe" (Hardy, 1940, p. 10). However, this also means that at 
least two thirds of his results were new at the time that Ramanujan discovered them. He had gone well beyond re-discovery to developing "startling" new results "to a remarkable extent", (Ramanujan's terms, Berndt \& Rankin, 1995, p. 21) and to an extraordinary new level.

Ramanujan always acknowledged that his inspiration came in the form of various kinds of revelations from his family gods, most notably from Namagiri and Narasimha, but certainly from other gods who were worshipped at the Sarangapani Temple in Kumbakonam, such as the horse headed avasara of Vishnu, Hayagriva, the god of knowledge and wisdom, and of education. For the western mind, this inspiration, when not denigrated, tends to be glossed as intuition. Here, there are three important points to make about Ramanujan's intuition, errors, and rigour of proof.

First, mathematicians often use intuition to derive conjectures, and to search for methods of approach to problems. In one sense, Ramanujan was no different; yet, in another sense, his intuition was extraordinary. Many results "apparently came to his mind without effort" (Ranganathan, 1967. p. 80), and he did anticipate an enormous amount of mathematics that was later to become important. His speed of calculation was prodigious, his ideas seemed to pour out at such a rate it was not possible to write them all down, and his solutions to problems were explained in one or two steps where other mathematicians (including those with expertise in the particular area) needed a page or so of working out.

Another term to describe Ramanujan's inspiration and intuition would be insight. The term insight "encapsulates the process in problem solving during which a previously unsolvable puzzle suddenly becomes clear and obvious" (Merrotsy, 2017, p. 20). Dehaene (1997, p. 151) has described this moment for mathematicians, when they "see" with their "mind's eye":

They say that in their most creative moments, which some describe as illuminations, they do not reason voluntarily, nor think in words, nor perform long formal calculations. Mathematical truth descends upon them, sometimes even during sleep.

Second, much has been made about errors, mistakes, false statements, completely wrong theorems, and the lack of rigour occurring throughout Ramanujan's thinking and results (for example Hardy, 1940, taken out of context; Nadathur, Desai, Nadathur, Rajasekaran \& Rajasekaran, 2014; Pressman, Young, Thomas \& Brown, 2016; Sykes, 1987). For example, in early correspondence to Ramanujan, and in response to receiving so many pages of theorems-without-proof, Hardy wrote:

I want particularly to see your proofs of your
assertions here. [i.e., for the results that Hardy
considered new and important]. You will
understand that, in this theory, everything
depends on rigorous exactitude of proof. (Berndt
\& Rankin, 1995, p. 47 , emphasis in original.)

To be sure, some conjectures about prime numbers were overstated and their ramifications too eagerly anticipated, but the reality is that only a handful, "at most five to ten formulas, are incorrect" (Berndt, Preface, Ramanujan Aiyangar, 2012, p. xiii). Some of the supposedly "false statements" were "false but correctable" (Berndt, Preface, Ramanujan Aiyangar, 2012, p. xiii), while some proved to be very fruitful indeed, leading to much deeper results (Hardy, 1940). And some of the results that were questioned, such as the astounding partition formula, turned out to be amongst Ramanujan's greatest successes.

The perception of lack of rigour was not helped by the way in which Ramanujan's results were recorded by him. Most entries in The Notebooks are bald statements of results, arrived at by arduous work, and when a proof was included in The Notebooks, it was indicated in only one sentence (Ramanujan Aiyangar, $1988,2012)$. There were very good reasons for this. Ramanujan cut his mathematical milk teeth on Carr's 
(1886) Synopsis, which would have served as a template for him. Moreover, paper was an expensive luxury that Ramanujan could not afford, and after working through a problem on his slate, erasing his working out with his elbow as he proceeded, he recorded just the final results on paper in his notebook. Again, the notebooks were not public documents: rather, they were a personal record and collection of what Ramanujan had discovered; he only needed the final results because he remembered how he had arrived at these results; and if others were to ask him about a proof of a result or the method used for a series of results he would be able to provide the details. When proofs of his highly advanced results were written up for publication, they did need tightening up and explication to make the deep generalisations and enormous leaps in logic accessible to others; and they did need refinement to fill in the gaps from traditional European mathematics that Ramanujan had not met, or had not derived by himself.

Third, it may have been the case that in classical Indian mathematics there was no conventional structure of proof used to validate of mathematical results. Mathematicians provided "reasoned justification" for their statements (Divakaran, 2018, p. 10), arguing from "direct perception, inference, analogy, and authoritative testimony" (Plofker, 2009, p. 12). This does not mean that rigorous demonstration and formal logic were not present in mathematical argument. And, in any case, Ramanujan certainly knew what constituted a proof. Even with his criticisms about rigour, Hardy was the first to acknowledge that Ramanujan "knew when he had proved a theorem and when he had not" (Hardy, 1921, p. liii). Many results may have "apparently came to his mind without effort. He was, however, aware that a good deal of intellectual effort would be required to establish [them]" (Ranganathan, 1967, p. 80).

In his correspondence, he refers to his "method", which he had developed over the previous eight years - the problem was, he had not found anyone who could appreciate it (Berndt \& Rankin, 1995, p. 81). When Hardy wrote, "send me your proof written out carefully (so that is easy to follow)" (Berndt \& Rankin, 1995, p. 87), what he really meant was that Ramanujan's argument was so terse that not even a leading European mathematician such as Hardy could easily follow it, and, as Hardy (1940) was the first to admit, some of the results defeated him completely. Ramanujan desperately needed a colleague with whom he could talk mathematics: Hardy was the first he had found; Ramanujan was prepared to listen, and to correct or improve on his results, and was learning from his mentor the art of writing mathematics.

Just like any other mathematician, Ramanujan did make extensive numerical calculations and from these would make deductions that would give rise to conjectures, followed by exploration of their plausibility, and then effort to prove the rigour of the result.

[Both Hardy and Berndt] firmly believe that Ramanujan created mathematics as any other mathematician would, and that his thinking can be explained like that of other mathematicians. ... As Ramanujan himself was aware, some of his arguments were not rigorous by then contemporary standards. Nonetheless, despite his lack of rigour at times, Ramanujan doubtless thought and devised proofs like any other mathematician, but with insights that surpass all but a few of the greatest mathematicians. (Berndt, Preface, Ramanujan Aiyangar, 2012, p. xiv.)

\section{Ramanujan's legacy}

Ramanujan was a singularity, in both the general and the mathematical senses of this word, and for much of his life he was a singularity in an academic desert. $\mathrm{He}$ was a self-taught mathematical prodigy, from a small, backward and superstitious rural town in southern India. "Out of such a place, from a poor family, came 
a mathematician so alive with genius!" (Kanigel, 1991, p. 1). His was a "transcendental order of genius" (Ranganathan, 1967, p. 34). He had "one gift which no one can deny - profound and invincible originality" (Hardy, 1921, p. lviii), and his mathematical work was ground breaking and unconventional, and reflected "astonishing individuality and power" (Kanigel, 1991, p. 372). Ramanujan "defies almost all the canons by which we are accustomed to judge one another" (Hardy, 1940, p. 1), but he was by anyone's judgement a very great mathematician, and unique. Certainly, Ramanujan was one of the most remarkable mathematicians of his time (Hardy, 1940), and, I would argue, of all time.

From a European (or western) perspective, Ramanujan's story shows that genius has no respect for cultural or social barriers: genius may be found anywhere, including in the most disadvantaged, unexpected and unforgiving places; and it needs to be recognised, acknowledged, understood, and nurtured. Ramanujan's work is particularly remarkable and valuable because his mathematical intuition and insights, and his methods of enquiry are completely unorthodox and so very much different from anyone else, past or present. His work also suggests that, at least in mathematics, creative products cannot be separated from the creative experiences that produce them.

The tragedy is that, by recording his discoveries without proofs in his notebooks, it has been very difficult to ascertain Ramanujan's thoughts, and for several topics it has not yet been possible at all. For example, the notebook that was lost resurfaced in 1976 and is now known as The Lost Notebook (Andrews, 2001; Ramanujan Aiyangar, 1988). In it we find that, with his continued work on modular forms and his new work on the mock theta function (Watson, 1936), Ramanujan had anticipated so much mathematics that was to come, such as the structure of the ideas that led to the proof of Fermat's Last Theorem, and, perhaps surprisingly, the mathematical framework for models used by theoretical physicists, including those for black holes. The Notebooks (Ramanujan Aiyangar, 2012) and The Lost Notebook (Ramanujan Aiyangar, 1988) continue to tantalise us with hints and suggestions that Ramanujan's thinking had so much more to offer, and has so much more to offer if only we can untangle and discern it. Ramanujan himself always humbly acknowledged that the inspiration for his discoveries came from the goddess Namagiri, saying that "An equation has no meaning for me unless it expresses a thought of God" (Ranganathan, 1967, p. 88).

\section{Acknowledgements}

A sabbatical grant from The University of Western Australia made it possible for the author to travel to Tamil Nadu to collect information first-hand about Ramanujan's life and the social and cultural milieu in which he lived, and to sight original documents and photographs of original documents at Srinivasa Ramanujan House, Kumbakonam, Ramanujan Institute for Advanced Study in Mathematics, Triplicane, Chennai, The Institute of Mathematical Sciences, Tharamani, Chennai, and Ramanujan Museum, Royapuram, Chennai.

I wish to thank the Master and Fellows of Trinity College Cambridge for their kind permission to use the photograph of Ramanujan taken in February 1919 shortly before he returned to India, and which is held at Trinity College Library.

\section{References}

Andrews, G. E. (2001). An introduction to Ramanujan's "lost" notebook. In B. C. Berndt \& R. A. Rankin (Eds.), Ramanujan: Essays and surveys (pp. 165-184). Providence, RI: American Mathematical Society. 
Berndt, B. C., Choi, Y.-S., \& Kang, S.-Y. (1999). The problems submitted by Ramanujan to the Journal of the Indian Mathematical Society. Contemporary Mathematics, 236, 215-256.

Berndt, B. C. \& Rankin, R. A. (1995). Ramanujan: Letters and commentary. Providence, RI: American Mathematical Society.

Berndt, B. C. \& Rankin, R. A. (Eds.) (2001). Ramanujan: Essays and surveys. Providence, RI: American Mathematical Society.

Carr, G. S. (1880). A synopsis of elementary results in pure and applied mathematics: Containing propositions, formuloe, and methods of analysis, with abridged demonstrations. [Volume I.] London, England: C. F. Hodgson and Son.

Carr, G. S. (1886). A synopsis of elementary results in pure mathematics: Containing propositions, formule, and methods of analysis, with abridged demonstrations. [Volume II.] Cambridge, England: Macmillan \& Bowes.

Dehaene, S. (1997). The number sense: How the mind creates mathematics. Oxford, UK: Oxford University Press.

Divakaran, P. P. (2018). The mathematics of India: Concepts, methods, Connections. New Delhi, India: Springer, and Hindustan Book Agency.

Fitzgerald, M. (2002). Did Ramanujan have Asperger's disorder or Asperger's syndrome? Journal of Medical Biography, 10, 167-169.

Guha, S. (1991). Mortality decline in early twentieth century India: A preliminary enquiry. The Indian Economic and Social History Review, 28, 371-391.

Hardy, G. H. (1921). Obituary notice: Srinivasa Ramanujan. Proceedings of the London Mathematical Society, s2-19(1), xl-xlix.

Hardy, G. H. (1940). Ramanujan: Twelve lectures on subjects suggested by his life and work. Cambridge, England: Cambridge University Press.

Hardy, G. H. (1967). A mathematician's apology. Cambridge, England: Cambridge University Press.
Hardy, G. H., Seshu Aiyar, P. V., \& Wilson, B. M. (Eds.) (1927). Collected papers of Srinivasa Ramanujan. Cambridge, England: Cambridge University Press.

Kanigel, R. (1991). The man who knew infinity. London, England: Abacus.

Katz, V. J. (2018). A history of mathematics: An introduction (3rd edition). New York, NY: Pearson.

Loney, S. L. (1893). Plane trigonometry [2 volumes]. Cambridge, England: Cambridge University Press.

Merrotsy, P. (2017). Pedagogy for creative problem solving. Abingdon, UK: Routledge.

Nadathur, S., Desai, S., Nadathur, S. \& Rajasekaran, S. (Producers), \& Rajasekaran, G. (Director). (2014). Ramanujan [Motion Picture. Languages: Tamil \& English]. India: Camphor Cinema.

Oxfam. (2019). Public good or private wealth? [Oxfam briefing paper, January.] Oxford, UK: Oxfam GB.

Plofker, K. (2009). Mathematics in India. Princeton, NJ: Princeton University Press.

Pressman, E. R., Young, J. \& Thomas, J. (Producers), \& Brown, M. (Director). (2016). The man who knew infinity [Motion Picture]. United Kingdom: Warner Bros.

Ramachandra Rao, R. (1920). In memoriam: S. Ramanujan, B.A., F.R.S.. Journal of the Indian Mathematical Society, 12, 87-90.

Ramanujan Aiyangar, S. (1914). Modular equations and approximations to $\pi$. Quarterly Journal of Mathematics, 45, 350-372.

Ramanujan Aiyangar, S. (1988). The Lost Notebook and other unpublished papers. New Delhi, India: Narosa.

Ramanujan Aiyangar, S. (2012). Notebooks of Srinivasa Ramanujan [2nd edition; 2 Volumes; edited by R.A. Rao]. [Reproduction edition of the author's manuscripts.] Mumbai, India: Tata Institute of Fundamental Research. 
Ranganathan, S. R. (1967). Ramanujan: The man and the mathematician. Bombay, India: Asia Publishing House.

Runco, M. A. \& Jaeger, G. J. (2012). The standard definition of creativity. Creativity Research Journal, 24(1), 92-96.

Stein, M. I. (1953). Creativity and culture. Journal of Psychology, 36, 311-322.

Stillwell, J. (2010). Mathematics and its history (3rd edition). New York, N Y: Springer.
Sykes, C. (1987). Letters from an Indian clerk. [Video documentary.] BBC. Retrieved from https:// www.youtube.com/watch?v=OARGZ1xXCxs

Watson, G. N. (1936). The final problem: An account of the mock theta functions. Journal of the London Mathematical Society, 11, 55-80.

Young, D. A. B. (1994). Ramanujan's illness. Notes and Records of the Royal Society of London, 48(1), 107-119. 